\title{
OS PRIMEIROS TEMPOS DE UMA IDÉIA QUE DEU CERTO 1984-1986
}

\author{
RICARDO FARRET
}

Não foram poucos os acontecimentos na história brasileira (a Proclamação da Independência, a Proclamação da República, a libertação dos escravos, para só citar alguns) que, visando autonomizar e fortalecer as bases, surgiram de iniciativas da cúpula. Mantendo as devidas proporções, a criação da ANPUR não fugiu à regra, resultado que foi de sinalizações dos órgãos oficiais de fomento, no início dos anos 80 . Lembro-me quando, em 1984, ocupando a coordenação do Programa de Pós-graduação em Planejamento Urbano da Universidade de Brasília, fui convidado pelo colega Lucio Grinover, então Diretor da FAU/USP, a participar de uma reunião, em São Paulo, que visava a criação de uma associação que congregasse os programas na área, desdobrando, de certa forma, uma idéia do sistema CNPq-Capes.

Outras reuniões se sucederam, e o trabalho de um pequeno grupo de docentes resultou na criação da ANPUR. Evidentemente, a história não foi tão simples e linear assim, já que no caminho houve muitas idas e vindas, incluindo o primeiro "racha" que acabou resultando na criação da congênere da ANPUR, a Antac. Criada e estatuída no foro de São Paulo, e tendo o colega Grinover como Presidente da Diretoria Provisória, a ANPUR foi fundada e constituída, inicialmente, pelos cinco programas de pós-graduação stricto sensu então existentes: FAU/USP, PUR/UFRJ, PROPUR/UFRGS, MDU/UFPE e UnB.

Em 1984, em São Paulo, concluído o seu mandato e cumpridas as metas a que se propôs (dar base legal e jurídica à Associação), a Diretoria Provisória promoveu a eleição da primeira Diretoria, de acordo com os estatutos, para o biênio 1984-1986, na qual fomos escolhidos: Ricardo Farret (UnB) para a Presidência, José Galbinski (UnB) para Secretário Executivo, e Martim
Smolka (PUR/UfrJ), Wrana Panizzi (Ufrgs) e Guilherme Varela (UFPE) para Diretores.

Ainda sem imaginar o desenvolvimento que a ANPUR iria ter nesses 15 anos de existência, a Diretoria eleita elaborou, na ocasião, um Plano de Trabalho fundamentado em três grandes linhas de ação: a formulação de uma política editorial para a área; a instituição de uma base financeira permanente; e a realização do I Encontro Nacional. Como se vê, propostas nada modestas que, até hoje, em especial as duas primeiras, freqüentam a agenda das sucessivas diretorias!

Em relação à política editorial chegou-se a cogitar três alternativas: revista específica da ANPUR; apoio às publicações existentes (Espaço \& Debates, Projeto etc.); ou apoio à criação de publicações periódicas no âmbito dos programas. Proposta, evidentemente, não decidida, e transferida à próxima Diretoria, numa sucessão que ocorre até a atual gestão. Como realização nesse campo, destaca-se a publicação dos três primeiros números do Boletim da ANPUR.

Quanto à sustentabilidade (termo inexistente à época) financeira, a Diretoria também trabalhou com algumas alternativas: prestação de serviços aos órgãos de governo (Ministério do Interior, Ministério do Desenvolvimento Urbano, CNDU, CNPq, Capes etc.) ou fora dele (Fundação Ford, por exemplo); cobrança de anuidade dos programas filiados; recebimento de doações institucionais "permanentes" (Capes, CNPq etc.). Como até hoje, os recursos para custeio vieram do apoio que o programa-sede da Diretoria disponibilizou, ou seja, o mínimo para manter a ANPUR em vida vegetativa.

Já em relação ao I Encontro Nacional, após inúmeras alternativas de formatação, ele foi realizado em Nova Friburgo, Rio de Janeiro, no período de 24 a 27 de junho de 1986. O formato deste Encontro reuniu 
oportunidade e engenhosidade, visando atender, no exíguo prazo disponível, os interesses da ANPUR e das agências de fomento então existentes: CNPq, Finep, CNDU e BNH. O Encontro reuniu cerca de 120 participantes, entre membros da Diretoria, convidados institucionais e membros dos três Grupos de Trabalho, organizados em torno das subáreas da ANPUR: planejamento regional, urbano e habitacional.

De comum acordo com as agências patrocinadoras, o I Encontro Nacional da ANPUR assumiu o formato de um multi-evento, constituído por um painel, "A questão urbana e regional na Constituinte"; uma conferência, "Política científica e tecnológica"; um encontro de trabalho, "Mudanças sociais no Brasil e a contribuição da ciência e tecnologia para o planejamento regional, urbano e habitacional"; e, espremida entre eles, a realização da Assembléia Geral, que no fundo era, para a ANPUR, dadas as circunstâncias, o evento mais importante desse verdadeiro happening científico.

Cabe ressaltar que, na ocasião, ainda não havia um "clima” favorável, por parte dessas agências, para o patrocínio de um Encontro, com o formato que hoje ele assume. Daí a engenhosidade do formato adotado, de modo a atender a todos os interesses em jogo. Com isso, e desde aquela ocasião, a ANPUR já demonstrava "jogo de cintura” para enfrentar, com sucesso, idiossincrasias institucionais de toda ordem.

O painel "A questão urbana e regional na Constituinte", coordenado pelo colega Luiz César de Queiroz Ribeiro, do PUR/UFRJ (hoje IPPUR), contou com a participação de profissionais de diversos segmentos da comunidade envolvida com a área de ação da ANPUR: Manoel André da Rocha (UFRGS), Cândido Malta Campos Filho (USP) e Berta Becker (UfRJ), pela academia; o saudoso colega Maurício Nogueira Batista, do Ministério do Desenvolvimento Urbano e Meio Ambiente (MDUMA), como representante da área técnicogovernamental, e, iniciando uma prática que se estende até hoje, um representante de organização não-governamental, o Padre Thierry Linard de Guertechin, indicado pela Conferência Nacional dos Bispos do Brasil (CNBB). Como convidado especial, também inaugurando uma prática que persiste até hoje, o Painel contou com a presença do Deputado Djalma Bom, então presidente da Comissão de Desenvolvimento Urbano da Câmara Federal.

O colega Emílio Haddad, da FAU/USP e IPT/SP, foi o responsável pela conferência científica que, nos encontros subseqüentes, foi ampliada com a participação, também, de um conferencista estrangeiro.

Pelo fato de ser o primeiro Encontro, havia uma extensa produção pulverizada e "represada" ao longo dos anos (e, seguramente, desconhecida tanto pelos programas como pelas agências). Essa produção, representada por pesquisas, teses, dissertações e trabalhos de consultoria e assistência técnica, muito provavelmente, não teria condição de ser enviada, em bases individuais, pelos seus diversos autores, distribuídos pelo território nacional. Daí ter a ANPUR "encomendado" quatro estudos que visavam identificar o perfil quantitativo e qualitativo dessa produção, bem como sistematizar, de acordo com parâmetros previamente por ela definidos, a produção nas suas três subáreas de ação: planejamento regional, urbano e habitacional. Esse trabalho, na ocasião, era de grande interesse para os organismos patrocinadores e para a própria ANPUR, que necessitava conhecer melhor o perfil da área.

Os consultores, responsáveis pelos quatro estudos que alimentariam o Encontro de Trabalho, tiveram como fonte de informação um levantamento realizado pelo PUR/UFRJ para a Finep, no qual fora registrada a produção da área, num total de 928 trabalhos. Após passar pelo crivo implacável da sistematização elaborada, não sem dificuldades pelos colegas Rainer Randolph e Ester Limonad, do PUR/UfRJ, chegou-se a um total de 548 trabalhos, sendo 111 na subárea regional, 304, na urbana, e 133, na habitacional.

O trabalho por eles elaborado, "Balanço quantitativo da produção técnica e científica em planejamento regional, urbano e habitacional - 1980-1986", apesar das dificuldades conceituais e operacionais, foi apresentado rigorosamente no prazo previsto. Para se ter uma idéia dessas dificuldades, os colegas Rainer Randolph e Ester Limonad, responsáveis pelo estudo, ressaltaram, não sem humildade, que "o tamanho deste trabalho, feito sem computador, pois pela natureza das informações colhidas, por sua heterogeneidade, pela falta de um padrão comum em sua apresentação, achamos (sic) melhor usar nossas próprias cabeças" (Anais do I Encontro da ANPUR, 1986, p.51).

Outras dificuldades enfrentadas referem-se à delimitação das subáreas, em que, conforme observam os consultores, "parece-nos discutível a aceitação de pesquisas físico-químicas de materiais de construção em 
geral, do prego à laje de cobertura, como produção concernente à problemática do planejamento regional, urbano e habitacional" (idem, p.57). Dificuldade maior foi enfrentada em relação ao conceito de urbano, um problema que persiste até hoje, que, segundo os autores, "por sua indeterminação enquanto categoria de análise, este termo é apropriado diferenciadamente" (idem, p.54). Assim, não seria o urbano o objeto de estudo, mas sim seus atributos, sua expressão no espaço físico e os processos de controle e regulação que a ele se referem. Na subárea regional, as indefiniçôes conceituais não foram menores.

Daí terem os consultores apontado a necessidade urgente de a ANPUR encaminhar a questão, o que foi sendo feito ao longo dos encontros subseqüentes, com a identificação das áreas temáticas, hoje mais ou menos consolidadas.

A subárea regional, a cargo dos colegas Wilson Cano e Leonardo Guimarães, da Unicamp, que se ocuparam de 111 trabalhos, mostra que, apesar do avanço significativo ocorrido nas últimas décadas em matéria de conhecimento, apresenta lacunas, como, por exemplo, uma confusão metodológica que faz que trabalhos sobre a Amazônia e sobre o município de Rio Branco, Acre, sejam apresentados na subárea regional, e, a idéia de região, como entidade autônoma, ignorando a economia nacional, quando, na verdade, segundo os autores, "o processo deveria ser inverso" (idem, p.15).

O Grupo de Trabalho encarregado de relatar o texto básico foi constituído pelos colegas Carlos Vainer e Hermes Tavares, do PUR/UFRJ, e Roberto Smith, da UFCE.

Na subárea de planejamento urbano, o texto básico a cargo do colega Celso Lamparelli, da FAU/USP, o autor observou, além de uma excessiva concentração da produção em São Paulo, a prevalência de análises empíricas e setoriais, que distanciavam a produção do enfrentamento mais direto em relação à grande lacuna da subárea: a indefinição de seus paradigmas e a falta de integração deles com as diferentes vertentes teóricas e metodológicas dos processos e padrões urbanos.

O Grupo de Trabalho encarregado de relatar o texto básico foi constituído pelos colegas Jorge Dantas (FAu/UsP), José Galbinski (UnB), Luiz Cesar Ribeiro (PUR/UfRJ), Pedro Jacobi (Neru) e pelo saudoso Carlos Nelson F. dos Santos, do Ibam.

No que se refere à subárea de planejamento habi- tacional, o texto básico esteve sob a responsabilidade da colega Ermínia Maricato, da FAU/USP, que foi além do levantamento elaborado para a Finep, consultando outras fontes de informação. A autora observa que a pesquisa na subárea "é recente e, além disso, o país conta com pouca tradição e pouco acúmulo de conhecimento em relação à pesquisa em tecnologia" (idem, p.39). O texto, mais do que apresentar um balanço da produção na subárea, mostra a visão da autora sobre a questão da tecnologia do ambiente construído, no Brasil. Mesmo assim, aponta para lacunas importantes na pesquisa, relativas tanto a fatores exógenos ao canteiro, como, por exemplo, a estrutura fundiária, o financiamento e o mercado habitacionais; como internos ao canteiro: organização da produção, qualificação profissional, condiçōes de trabalho etc.

O texto foi relatado pelo Grupo de Trabalho constituído pelos colegas Alex Abiko, da Poli/Usp, Nabil Bonduki, da EBA e Bruno Dauster M. e Silva, da Secretaria do Bem-Estar Social da Bahia.

O último - e não menos importante - dos eventos do I Encontro Nacional foi a Assembléia Geral da ANPUR. Inaugurando uma prática que seria mantida por muitos anos, a Assembléia foi realizada à noite. Essa prática não passou despercebida pelo filósofo José Arthur Giannoti, que, anos mais tarde, como conferencista convidado para o Encontro de Águas de São Pedro, São Paulo, abriu sua exposição "agradecendo à ANPUR, Associação Noturna de Planejamento Urbano e Regional, pelo convite formulado"!

Com uma agenda "quente", na qual se destacava a questão de novas filiaçôes, a Assembléia, que, obviamente, entrou noite adentro, enfrentou o tema da ampliação do seu quadro associativo, cujas sondagens sempre esbarravam na ausência de uma definição mais clara do campo e, por extensão, das instituições que a ANPUR deveria congregar. "As mesmas questôes que haviam, por longo tempo, bloqueado a organização da comunidade científica da área, continuaram a cobrar o seu tributo, criando um impasse na Associação" (idem, p.79).

Essencialmente, duas questōes polarizaram os debates na Assembléia. A primeira dizia respeito à conformação científica da área, envolvendo a sua natureza e pluridisciplinaridade no tratamento de um mesmo objeto, o urbano e o regional. A segunda referia-se à natureza das instituiçōes que uma associação científica da área deveria congregar, considerando a sua particularida- 
de de envolver intervenções governamentais e práticas extra-universitárias que, dessa forma, colocariam dificuldades para uma clara delimitação da comunidade científica em planejamento urbano, regional e habitacional. Após uma noite inteira de discussão, a Assembléia conseguiu elaborar um perfil para a ANPUR que reconhecia como legítimas as diferentes formas de abordagem da questão urbana e regional, como, também, a necessidade de abrir a Associação a toda e qualquer instituição que estivesse voltada para temas e discussões, globais ou particulares, dessa questão. Deste modo, o novo Estatuto, então aprovado, ao mesmo tempo que reiterava a natureza institucional das filiações, flexibilizava o processo de inserção de novos membros, na medida em que se abria para "programas e entidades que desenvolvem atividades de ensino e/ou pesquisa no campo dos estudos urbanos e regionais, dentro ou fora da universidade".
Essa abertura, no entanto, veio condicionada à preservação, por parte da ANPUR, dos compromissos fundamentais com a Universidade e os programas universitários da área. No essencial, tratava-se de conferir às instituiçōes universitárias uma maior responsabilidade nas tarefas de articulação da comunidade. Assim, como forma de contemplar essas diferenças, o novo Estatuto definia dois tipos de vinculação com a ANPUR: membros filiados, representados pelos programas de pós-graduação stricto sensu; e membros associados, para as demais entidades. Essas diferentes vinculaçôes implicariam representações numericamente diferenciadas na composição da Diretoria e da Assembléia Geral.

Essa descrição da Assembléia, obviamente, não reflete o "clima" de intensos e acalorados debates ali ocorridos, amenizados, pasmem, pelo nada singelo ronco de um colega pernambucano, quando o dia já amanhecia! 